\title{
Listening to Saudi EFL Learners' Voices: Demotivating Factors Affecting Learning
}

\author{
Wael A Holbah \\ English Language Institute, Jazan University, Jazan, Saudi Arabia \\ Vipin Sharma \\ English Language Institute, Jazan University, Jazan, Saudi Arabia
}

\begin{abstract}
A plethora of research has considered motivation instrumental in achieving the requisite objectives in learning a language regrettably overlooked the most critical component called demotivation that indubitably affects the learning process substantially. The researchers have taken the daunting task to figure out the demotivating factors that affect Saudi learners' English proficiency. The research is qualitatively based on the responses obtained from semi-structured informal interviews with twenty-six respondents and classroom observation inputs from over 125 students learning English as a foreign (EFL) language at Jazan University in Saudi Arabia. The sample of this study responded to a self-structured questionnaire to get qualitative data and after twofold data analysis, six demotivating factors related to students; teachers; environment (internal \& external); attitude towards EFL learning; course materials, and time constriction were identified. The findings and suggestions reckon students, teachers, parents, and administrators to give utmost priority to address demotivation factors to facilitate even EFL learning to timely achieve not only the prerequisite learning outcomes but may also lead learners to be autonomous, infuse interest, confident with 21st-century skills, better teacher-learner relationship, and change in cognitive behavior, and non-cognitive aspects which includes perception, attitude, beliefs and willingness to learn English language.
\end{abstract}

Index Terms - motivation, demotivation, Saudi learners, English as second/foreign language

\section{INTRODUCTION}

The craze to learn English as a foreign language (EFL) in Saudi Arabia has been ever-increasing day by day. In the early times, the English language was always perceived to be taught only to the people who were eager to learn English. However, the English language today has become Lingua Franca, which is required to uphold better business relations to interact with people of other countries working in Saudi Arabia and on international platforms. Recent research revealed that Saudi learners showed that they are instrumentally motivated to learn English for the reason that it meets university criteria, but a few studies have shown otherwise.

But since successive research hasn't acted on plans tackling demotivating factors to address serious concerns is now happening under duress when the EFL teachers and learners are under huge pressure to achieve learning outcomes making it all shaky. To compound the fact that it has become a burning issue in academia, instant actions are also not doing it any favors. EFL learners have great potential and enormous talent but poor decision-making has wrecked all the concerned. Education First English Proficiency Index (EF EPI, 2020) in its analysis of English skills showed that the English language proficiency level in Saudi Arabia is very low with an EF EPI score of 399, which falls at eighth place in the Middle East region. It also revealed that it was on the 97th position in a hundred countries list...English proficiency in the region is by far the lowest of any region in the world. We should take it a wake-up call to rise to the occasion and ignore critics who care about "compromising the silver job" and take remedial action before it becomes too late.

A plethora of research has considered motivation instrumental in achieving the requisite objectives in learning a second/foreign language regrettably overlooking the most critical component called demotivation that indubitably affects the learning process substantially. This triggered a spark to explore more why Saudi learners aren't motivated to learn English and if they are motivated then why don't they perform as expected. Therefore, this study undertakes to investigate the causal demotivating factors that thwart their English proficiency. The research will further underscore the forms and concepts of motivation, its relevance for EFL teachers to exercise in the formal settings to bring in the tangible transformation in learners' attitude and motivation towards EFL acquisition. Alongside, the major factors responsible for demotivating learners are also enquired into to get some feasible and pragmatic solutions that may lead learners to change their perception, attitude, and willingness to learn the English language. Accordingly, the study is a seminal attempt to examine the major demotivating factors impeding Saudi learners from learning the English language as a foreign language in Saudi Arabian EFL learners' context.

\section{LITERATURE REVIEW}


Motivation is a dynamic and broader concept that encapsulates giant space across disciplines. Dornyei and Otto (1998) describe it as a dynamically changing cumulative arousal in a person that initiates, directs, coordinates, amplifies, terminates, and evaluates the cognitive and motor processes whereby initial wishes and desires are selected, prioritized, operationalized, and (successfully or unsuccessfully) acted out. Guay et al. (2010) refer to the reasons underlying behavior and Broussard and Garrison (2004) state motivation as the attribute that moves us to do or not to do something. A plethora of research has been undertaken across disciplines suggesting motivation operating through teaching practices despite illustrating its pros and cons. We have included studies published in the last three decades to comprehend in a better perspective.

Motivation has gone past many development stages from intellectual behavior adaptation to self-regulation theory (Schunk \& Zimmerman, 2007). In between, a strategy on rendering autonomy to learners in the classroom and a strategy for revitalizing motivation via collaborative or cooperative learning techniques (Hidi \& Harackiewicz, 2000) had also been exercised. Today, we need motivation for our learners to attain lifetime multi-skills eventually developing critical thinking to face global challenges studying at university. These future skills have been argued as assorted mechanisms as inferences drawn by inductive or deductive reasoning (Willingham, 2007); evaluating (Case, 2005), and making decisions or solving problems (Willingham, 2007).

A wealth of empirical evidence on motivation exists, suggesting several conclusions; however, motivation in language learning was embarked on only in the last decade of the twentieth century; Dornyei (1990 to 2010) considers motivation one of the main determinant of language accomplishment and Oxford and Shearin (1994) motivation determining the extent of active or personal involvement second language learning; and later assumed by many prominent researchers (Dornyei, Csizer \& Nemeth, 2006) in the English as a second or foreign language learning and still many on the way. However, with the new research in ESL/EFL acquisition, there has been a paradigm shift to a new concept called demotivation, which is also considered as "another side of motivation (Falout and Maruyama, 2004; Kikuchi \& Sakai, 2009b)".

Contrary to motivation in language learning, the term demotivation has never been measured so grave and overlooked, which imposed severe threats and challenges for the EFL community. Dornyei (2005) approves this fact "... in spite of their great significance, demotivation has received very little attention either in mainstream psychology or L2 research." This century has witnessed glimpses of a few studies reflecting upon this grave issue to consider demotivation a novice, but a valuable concept in second/foreign language learning. Dornyei (2001) could map out the hidden side of the coin defining demotivation as "... specific external forces that reduce or diminish the motivational basis of a behavioral intention or an ongoing action; however, he doesn't consider all negative influences as a demotivating factor and argues that a strong negative factor (categorized nine demotivating factors) restrains the current motivation, with some other positive motives still remaining and ready to be activated." The elucidation gives flexibility and dynamics to the concept that negative factors deterring motivation may be diminished by powerful positive factors inducing motivation. Flout and Falout (2004) feel that motivation pushes learning for life whereas demotivation cuts learning short. Yan (2009) stated demotives as the negative counterparts of motives and Hu (2011) described demotivating factors that impede learners' learning motivation. The relevant research on demotivation would facilitate teachers and learners in better understanding of motivation theoretical concepts eventually help to lessen the demotivating factors affecting development in EFL learning. The researchers have varied opinions underscoring the demotivation factors as internal and external. Alike, Ushioda (2001) and Kim and Seo (2012) consider extrinsic demotives, conversely, Dornyei $(2001,2005)$ states it intrinsic factors, which has been further emphasized in the studies by other elite researchers (Hirvonen, 2010; Jomairi, 2011; Yan, 2009).

On giving adequate details on worldwide studies on motivation and demotivation, many studies have dealt with the demotivation factors affecting Arabic EFL learners' language learning (Javid, Asmari, \& Farooq, 2012; Alhuqbani, 2009; Al-Tamimi, \& Shuib, 2009; Keblawi, 2005; Dhaif-Allah, 2005). The researchers have found EFL learners energetic and hardworking but unable to display interest in language learning. This also led the diagnostic approach to find negative factors (demotivating) along with the positive factors (motivation) affecting learners' perceptions and attitudes towards language.

We often observed that most of the students are instrumentally motivated and learn the English language for studying abroad and communication; however, Qashoa (2006) examined the students' integrative and instrumental motivation for learning the English language and identified the factors affecting motivation. Abu Baker, Sulaiman, \& Rafaai (2010) emphasize the identification of learners' demotivating orientations at the beginning of a language course for making decisions on the choice of language to be learned, the learners' activities, the learners' expectations on language learning, etc. Keblawi (2006) in research conducted in Israel explored the factors affecting negatively learning English. Hirvonen's (2010) in his study on Arab students in Finland found instrumental and integrative demotivating factors confirming the dominance of positive attitudes towards the English language trounce demotivation. Many scholars' findings showed that despite all concerted efforts, EFL learners couldn't accomplish and display tangible results as expected (Javid \& Al-Khairi, 2011; Al-Jarf, 2008).

The Ministry of Higher Education is determined to enhance students' English proficiency level ensuring all resources required to contribute to English language learning both at school and tertiary level. The initiatives have produced results but still miles to go to achieve the requisite objectives. The researchers have made a seminal attempt to look into 
the demotivating factors that deter Saudi EFL learners' language learning. A better perspective on demotivating factors would enable all to evolve strategies that boost and encourage both teachers and learners to timely accomplish the desired learning outcomes. The study tries to discover why the English proficiency level in Saudi Arabia is not as expected accentuating major negative effects that demotivate Saudi EFL learners.

\section{RESEARCH OBJECTIVES}

The objectives of this study are fourfold:

(a) To investigate the major demotivating factors affecting learners' language learning

(b) To learn how teachers can encourage learners to overcome the demotivating factors,

(c) To extract the most prominent demotivation factor that affects learners' EFL learning

(d) To review best practices used in tackling the demotivating factors

\section{METHODS}

\section{A. Participants}

The participants of this study consist of all Saudi undergraduate male students studying in the preparatory year at the Jazan University of Saudi Arabia and have been studying the English language as a compulsory subject in the College of Science.

\section{B. Instruments}

The research is qualitatively based on the responses obtained from semi-structured informal interviews with twentysix respondents and classroom observation inputs from over 125 students learning English as a foreign (EFL) language at Jazan University in Saudi Arabia. The qualitative data from the interviews were conducted after the observation data collection to get a deeper sense and better interpretation of the results. The tools for the research are the observational inputs from the EFL learners in the classroom and semi-structured interviews in regard to the demotivating factors in learning English as a foreign language. As for the semi-structured interview, this was conducted with ten students each semester. The interview sessions were conducted at the end of the semester at the students' convenience.

\section{Analysis}

The data (observatory and interviews) were segregated and organized to scrutinize the demotivating factors affecting Saudi learners' EFL learning. The process was a bit tedious and time-consuming to analyze each response to its requisite response on the given six demotivating factors.

\section{RESUlTS AND DisCUSSION}

The results were analyzed mainly on six demotivating factors: The results have ensued six major causal demotivating factors that hinder learners' language learning. These are related to the student, teacher, environment, attitudes, course material, and time constriction-related factors enumerated herewith.

Students-related Demotivation factors

The students were initially motivated to learn the English language but struggled and faltered in the beginning eventually improved from the sedate start. The researchers were teaching groups of heterogeneous students who in the majority attended classes regularly. There were three to four teachers teaching reading, writing, listening, and speaking skills separately to each group. The commencement of the course teaching made students uncomfortable facing difficulties in learning lengthy textbooks on all English skills. They were shy, hesitant, and resisted responding in the class making one-way communication and teacher-centered. Despite a few students who were reasonably good in English, most of the students were quite low in English proficiency because they learned English at school just to pass the exam. The researchers observed negative reactions to the textbook (texts), English as a medium, lack of basic knowledge of English, poor vocabulary, poor grammar, poor reading, and writing skills, etc. This was further confirmed with the responses gathered in interviews. Later on, the students gained momentum as the teachers evolved and manipulated their teaching strategies. The participation, involvement, and interaction in the classroom developed positive feelings surmounting their resistance, performance pressure, evaluation panic, and anxiety. It brought changes in their behavior, attitude towards the English language, improved abilities, self-confidence, self-worth, and self-belief enhancing their sense of competence. Eccles \& Wigfield (2002) mentioned that individuals should be more motivated to the extent that they feel they are in control of their own successes and failures.

Teachers-related Demotivation factors

Students not keen on learning the English language made the researchers introspect and reflect upon their own teaching techniques, course contents, and other factors that may affect students' interest in language learning. This was the result of what the researchers went through the studies related to teachers found as one of the dominant demotivation factors (Oxford, 1998; Ushioda, 1998; Dornyei, 2001; Keblawi, 2005; Kikuchi, 2010). The students opined on the teacher's unclear English pronunciation, speed, use of difficult vocabulary, fast teaching pace, strict or flexible, teacher's behavior, ignoring students' interest, taking up course directly, etc. were all beyond the ability, scope, 
and knowledge of students. Most students were blank when asked questions on the topics taught in class and unable to complete home assignments. Therefore, we have considered this factor crucial to demotivating Saudi learners. Also, Sharma (2018) opines that EFL teachers through implementing sound motivational strategies may enhance students' motivation, whereas naive behavior tends to affect students' motivation. Indeed, the results unveiled negative attitudes toward EFL teachers. Furthermore, the teacher has a special role and place in students' life as Krashen (1982) claims that "...the effective language teacher is someone who can provide input and help make it comprehensible in a low anxiety situation." This has sounded an alarm for the teachers to evolve, try new methods, prepare study materials matching students' level, use of latest technology, alter teaching styles, motivational techniques, beliefs, and attitudes to motivate the students to attain English proficiency.

Environment-related Demotivation Factors

This is one of the most critical factors affecting students' language learning. This includes both internal and external where internal is related to the classroom and external denotes the informal settings. Students initially encountered problems: lack of types of equipment- computers, audio, and video materials, speakers, etc., which affect the quality of teaching. But the same was addressed immediately and teachers used technology to conduct activities that allowed students to participate and enhance their cognitive skills. The students don't get ample opportunities to practice English and study English subjects as compulsory to promote to the next class. The parents, teachers, and peers should assist students to read and using English in real-life situations. The teachers plan and prepare activities wherein students partake in pairs or group activities to solve problems or express opinions on specific topics. Providing a hassle-noisefree language learning environment in the classroom avoids distraction, resulting in increased concentration, focus and motivates the students, and instills confidence. We often observe that an unhealthy classroom environment makes learners anxious, which challenges students' learning effectiveness and motivation. Alike, the monotonous classroom atmosphere leads to students' lack of interest, absence from class, and feel sleepy. The finding indicated that teachers created a classroom environment conducive to language learners and left no scope for them to complain. The conclusion matches the outcomes of many studies that display the attitude of classmates, compulsory nature of English study, friends' attitudes, inactive classes (Falout and Maruyama, 2004; Kikuchi, 2009; Sakai \& Kikuchi, 2009), however, don't agree on, the inappropriate level of the lessons and inadequate use of school facilities such as not using audio-visual materials, which are found better in the context of this study.

\section{Attitude towards EFL Learning}

Mentioned in the students' related factor, students displayed resistance and passive attitude towards the English language because of many aforesaid reasons. The students had negative attitudes towards EFL since they couldn't find content related to their objectives of specialization and took no interest in English. Luu (2011) stated that students facing a huge volume of difficult grammar and vocabulary often demonstrate widespread anxiety. It was observed that some students have a negative attitude towards English speaking community creating demotivation. Gardner (1985) affirms that language learners' attitude towards the target culture and its people has a considerable influence on their learning achievement and a learner cannot learn a language effectively if he has a negative attitude towards the country, people, and culture of the target language. Thus, the onus was on the teacher to teach the importance of the English language in today's scenario and convince them of its uses in a career to create interest in learning the English language. Cheng and Dornyei (2007) argued that teachers, in the teaching process, can foster students' motivation to learn by familiarizing learners with the L2 culture and L2-related values in order to increase their positive attitude towards the target language-speaking community. Displaying panache and patience in equal measure, the teacher could convince students to maximize their implausible talent and incredible potential in language learning. Though, sometimes they got away to innocuous reading activities with the English language someway off the target. But they indeed recovered and improved their language skills from the sedate start using their time and efforts. Soon after, they saved their best and, along with a genius and humane teacher, helped accomplish the requisite learning outcomes.

Course Materials-related factors

The results showed that the students found the textbook bit lengthy with intricate contents. They were grappled with odd situations where they couldn't comprehend the contents of the lecture and felt demotivating. It led to the monotonous classroom environment, without any learning, unseen chapters and topics with difficult texts, new vocabulary, etc., in all four skills. Many studies had similar findings on this factor, which were demotivating for the students. Tran and Baldauf (2007) stated that the students perceived textbooks as demotivating; however, Kikuchi (2009) found uninteresting contents of the texts, out-of-date topics, too long and difficult texts, difficult textbooks books, etc. leading to students' demotivation. Sakai \& Kikuchi (2009) discovered learning contents and materials considered as strongly demotivating, and Bahramy and Araghi's (2013) revealed dull and boring texts and subjects not related to daily life subjects, too much grammar, and not following a steady, step by step schedule identified as the second most demotivating factor for students in learning English. The results herein differ with these researches marginally as the students progressed and comprehend the texts, grammar and partake in all the activities conducted in the class or given as assignments. Therefore, it may partially be considered as a demotivating factor in the context of this study.

Time Constriction-related factors

The researchers considered this very vital in the Saudi Arabian context because firstly, the learners don't use the English language in daily life, secondly, they don't get ample time to study English and the 'obligatory nature of 
English language course' since they have to focus more on their major subjects. The students need time to read texts, write summaries, assignments, problem-solving tasks, and other activities not specific to English programs but mainly on other core subjects. Parents and teachers may guide them to work out a schedule by which they can devote time in equal measure to all subjects.

The second objective of the study, how teachers can encourage learners to overcome the demotivating factors, has largely being discussed in teacher-related demotivating factors. The teacher has to be active, alert, and visionary to foresee the main causes that may affect the language learning process. Instant and contingency plans, attractive and interesting activities at par with learners' level of language competence, one-on-one interaction, creating and maintaining a conducive classroom environment, cordial relations, prompt feedback, and controlled evaluation are a few measures that can diminish demotivating factors to the greater extent.

The next objective, to identify the most prominent demotivation factor that affects learners' EFL learning, was a much difficult task of the study because all factors affect either way; directly or indirectly; internal or external and in virtual settings. The researchers on the basis of discussion with colleagues and data analysis found the environmentrelated demotivation factors as the most prominent and dominant affecting learners' interest and language proficiency. The onus lies on all concerned; teachers, parents, peers, administrators to look into these factors giving utmost priority. A concrete system and mechanism should be put in place encapsulating guidance, counseling, support, redress mixed-ability learners' problems, encouraging cooperative and collaborative learning by students' taking part in pairs or group tasks; rationalize syllabus, textbook content; environment to promote English at all levels; giving students' autonomy to choose activities may together bear constructive and tangible results in bringing excellence in language learning.

What best practices do we use to tackle the demotivating factors was the last objective to overcome all the problems and challenges EFL learners face today. The researchers firmly believe that if a teacher comes with a heart, learners come with the heart and the soul. Comprehending this sentence makes teachers comfortable to evolve, devise, plan and organize their efforts to promote EFL learning amongst learners. Furthermore, Sharma (2018) proposes:

Nearly all the problems can be addressed by proper teacher counseling, teacher training and workshops on teaching methods, curriculum design, course specification, students need analysis, teaching style and strategies, continuous teacher evaluation, students' feedback, developing $21^{\text {st }}$-century skills, use of tools and websites in teaching plan, multiple intelligences, integrating ICT, understanding educational goals and objectives in national policies for education and using multilingual approaches in pursuit of Saudi Vision 2030.

For that reason, structuring tasks and activities matching learners' interest and proficiency level, setting goals, continual monitoring in behavioral changes, interest and attitude; friendly, democratic, and controlled behavior with learners; innovative teaching practices, judicious use of motivational techniques, committed and competent teachers, sound feedback and evaluation process, and teachers' stability with the group; noise-free learner-centered classroom environment; use of latest technology, exploiting smartphones and students' interest to use social applications: Facebook, WhatsApp, Twitter, snap chat, etc., in the language learning process are a few best practices that the talented and intellect EFL teachers exercise in their teaching today.

\section{CONCLUSION}

Aforesaid findings and discussion give an ample understanding of both internal and external factors that mostly demotivate learners. The results also revealed significant points on demotivating factors for second/foreign language learners and can negatively sway the learner's attitudes and behaviors, lower classroom environment, teacher's motivation, and result in everlasting dismal learning outcomes.

The most salient finding is that among six demotivating factors, the most concerned one was the environmentrelated factors; while the least concerned one was the teacher-related factor. All concrete observations and findings if adhered to in the letter and spirit would indubitably stimulate students' engagement and interest, inculcate a positive attitude and a sense of respect towards the English language. In general, all factors that affect students' language learning should be duly taken care of to avoid any vulnerability to motivate and encourage learners to enhance their English language proficiency. The uniqueness of this work lies in its findings where researchers have tried to come up with results and suggestions having dimensions that directly or indirectly influence Saudi EFL learners' motivation.

Lastly, we should come out with all guns blazing against all demotivating factors to allow EFL learners to get high English language proficiency. We absolutely believe that 'There is still more to explore to demotivation factors affecting English language learning'.

\section{ACKNOWLEDGEMENTS}

The authors wish to thank English Language Institute, colleagues and students for their immense support in completing the work. 


\section{REFERENCES}

[1] Abu Baker, K., N.F., Sulaiman, and Z.A.M., Rafaai. (2010). "Self-Determination Theory and Motivational Orientations of Arabic Learners: A Principal Component Analysis", GEMA Online TM Journal of Language Studies 10: 1, pp. 71-86.

[2] Alhuqbani, M.N. (2009). A Study of Saudi Police Officers' Motivations and Attitudes for Learning English as a Foreign Language. King Saud University Journal of Language and Translation, 21, 31-55.

[3] Al-Jarf, R. (2008). The Impact of English as an International Language (EIL) upon Arabic in Saudi Arabia. Asian EFL Journal, 10(4), 193-210. Retrieved 31 July 2021 from: http://www.asian-efl

[4] Al-Tamimi, A., and Shuib, M. (2009). Motivation and Attitudes Towards Learning English: A Study of Petroleum Engineering Undergraduates at Hadhramout University of Sciences and Technology. GEMA Online Journal of Language Studies, 9(2), 2955 .

[5] Bahramy, M., \& Araghi, M. (2013). The Identification of demotives in EFL university students. International Journal of Basic and Applied Science, 1(4), 840-845.

[6] Broussard, S. C., \& Garrison, M. E. B. (2004). The relationship between classroom motivation and academic achievement in elementary school-aged children. Family and Consumer Sciences Research Journal, 33(2), 106-120.

[7] Case, R. (2005). Moving critical thinking to the main stage. Education Canada, 45(2), 45-49.

[8] Cheng, H.F., \& Dornyei, Z. (2007). The use of motivational strategies in language instruction: The case of EFL teaching in Taiwan. Innovation in Language Learning and Teaching, 1, 153-174.

[9] Dhaif-Allah, A. (2005). An exploration of Saudi students' integrative and instrumental motivation for learning English. Occasional Papers in the Development of English Language Education, 39, 55-113.

[10] Dornyei \& Otto, I. (1998). Motivation in action: A process model of L2 motivation. Working Papers in Applied Linguistics (Thames Valley University, London), 4, 43-69.

[11] Dornyei, Z. (2001). Teaching and Researching Motivation. Harlow, England: Longman.

[12] Dornyei, Z., Csizer, K., and Németh, N. (2006). Motivation, language attitudes, and globalisation: A Hungarian perspective", Clevedon, [England]: Multilingual Matters.

[13] Eccles, J. S., \& Wigfield, A. (2002). Motivational beliefs, values, and goals. Annual Review of Psychology, 53, 109 -132.

[14] English Proficiency Index- EF EPI. (2020). The world's largest ranking of countries and regions by English skills (2020 edition). Retrieved on 29th May 2021 from: https://www.ef.com/wwen/epi/regions/middle-east/saudi-arabia/

[15] Falout, J., \& Maruyama, M. (2004). A comparative study of proficiency and learner demotivation. Jalt Publications. Retrieved March 28, 2012, from http://jalt-publications.org/tlt/articles/447-comparative-study-proficiency- and-learner-demotivation

[16] Falout, K., \& Falout, M. (2004). The other side of motivation: Learner demotivation. In K., Bradford-Watts, C., Ikeguchi, \& M. Swanson, M. (Eds.), JALT 2004 Conference Proceedings (pp. 280-289). Tokyo: JALT.

[17] Gardner, R. C. (1985). Social psychology and second language learning: The role of attitudes and motivation. London: Edward Arnold.

[18] Guay, F., Chanal, J., Ratelle, C. F., Marsh, H. W., Larose, S., \& Boivin, M. (2010). Intrinsic, identified, and controlled types of motivation for school subjects in young elementary school children. British Journal of Educational Psychology, 80(4), 711-735.

[19] Hidi, S., \& Harackiewicz, J. M. (2000). Motivating the academically unmotivated: A critical issue for the 21st century. Review of Educational Research, 70(2), 151-179.

[20] Hirvonen, M. (2010). Demotivation in learning English among immigrant pupils in the ninth grade of comprehensive school. Jyväskylä: University of Jyväskylä.

[21] Javid, C. Z., Asmari, A. A., \& Farooq, U. (2012). Saudi Undergraduates' Motivational Orientations towards EnglishLanguage Learning along Gender and University Major Lines: A Comparative Study. European Journal of Social Sciences, 27(2), 283300.

[22] Javid, C. Z., \& Khairi, M. H. (2011). The role of pleasure reading in enhancing reading speed and reading comprehension. Arab World English Journal, 2(4), 219-256.

[23] Keblawi, F. A. (2005). Demotivation among Arab learners of English as a foreign language. Proceedings of the Second International Online Conference on Second and Foreign Language Teaching and Research: Initiative, Innovation, and $\begin{array}{lllll}\text { Inspiration. } & \text { September } & 16-18, & \text { Retrieved } & \text { from }\end{array}$ http://www.readingmatrix.com/conference/pp/proceedings2005/keblawi.pdf

[24] Kikuchi, K. (2009). Listening to our learners' voices: What demotivatings Japanese high school students? Language Teaching Research, 13, 453-471.

[25] Kim, T., \& Seo, H. (2012). Elementary school students' foreign language learning demotivation: A mixed methods study of Korean EFL context. The Asia Pacific Education Research, 21(1), 160-171.

[26] Luu, T. T. (2011). EFL learners' motivation revisited. Theory and Practice in Language Studies, 1(10), 1257-1272.

[27] Oxford, R. \& Shearin, J. (1994). Language learning motivation: Expanding the theoretical framework. The Modern Language Journal. 78(1), 12-28.

[28] Oxford, R. (1998). The unravelling tapestry: Teacher and course characteristics associated with demotivation in the language classroom. Unpublished paper presented at the TESOL 98 Congress, Seattle, WA.

[29] Qashoa. S. (2006). Motivation among learners of English in the secondary schools in the eastern coast of the UAE. Dubai: Institute of Education- British University.

[30] Sakai, H. \& Kikuchi, K. (2009a). An analysis of demotivators in the EFL classroom. System 37, 57-69.

[31] Sakai, H. \& Kikuchi, K. (2009b). Japanese Learners' Demotivation to Study English: A Survey Study. JALT Journal, 31 (2), 183-204.

[32] Schunk, D. H., \& Zimmerman, B. J. (2007). Influencing children's self-efficacy and self-regulation of reading and writing through modeling. Reading \& Writing Quarterly, 23(1), 7-25. 
[33] Sharma, Vipin, (2016). Perceptions and Perspectives on Saudi Students' Productive skills and Communicative Competence in English as a Foreign Language: A Critical Study. Munich, GRIN Verlag. Retrieved 20 July 2021 from https://www.grin.com/document/350899

[34] Sharma, Vipin. (2018). Influence Factors in Students' Motivation for Communicative Competence in English: A Case Study in Saudi Arabia. The Journal of Literature, Languages and Linguistics, vol.50, pp. 37-47.

[35] Tran, T. T. T., \& Baldauf R. B. Jr. (2007). Demotivation: Understanding resistance to English language learning - The case of Vietnamese students. Journal of Asia TEFL, 4(1), 79-105.

[36] Ushioda, E. (1998). The role of motivational thinking in autonomous language learning. In E.A Soler, \& V. C. Espurz (Eds.), Current issues in English language methodology (pp. 77-89). Castelló de la Plana, Spain: Universitat Jaume I.

[37] Willingham, D. T. (2007). Critical thinking: Why is it so hard to teach? American Educator, 31(2), 8-19.

[38] Yan, H. (2009). Student and teacher demotivation in ESL. Asian Social Science, 5 (1), 109-12.

Wael A Holbah has obtained his master's and doctoral from Australia. He is currently working as an assistant professor and Vicedean for scientific research and academic development at English Language Institute, Jazan University, Jazan, Saudi Arabia. His research interests include second language acquisition, TESOL, sociolinguistics, applied linguistics, and CALL. Prof. Wael Holbah has written many articles in national and international journals of repute.

Vipin Sharma (Corresponding author) received an M.A. from Osmania University in Sociology, an M.A. from Maharishi Dayanand University Rohtak in English (1997), and a Ph.D. in American Literature. He is currently a faculty at English Language Institute, Jazan University in Jazan, Saudi Arabia. His research interests include second language acquisition, sociolinguistics, ecocriticism, and American literature. Prof. Vipin Sharma has contributed more than sixty articles in national and international journals of repute. He has authored two books and edited six books. 